\title{
Early Life Transitions of Canadian Youth: Effects of Family Transformation and Community Characteristics
}

\author{
Zenaida R. Ravanera \\ Fernando Rajulton \\ Population Studies Centre \\ University of Western Ontario \\ London, Ontario \\ Thomas K. Burch \\ Sociology Department \\ University of Victoria \\ Victoria, British Columbia
}

\begin{abstract}
This paper looks at the impact of family transformation and community characteristics on the timing and sequences of early life transitions of Canadians born in 1971-75. Using event history techniques of analysis, the effects on school completion, start of regular work, and home-leaving are examined using a data set that merged the 1995 General Social Survey of the Family with data derived from the enumeration areas of the 1996 Census. The results show that family disruption impacts negatively on the transition to adulthood. And, mother $=\mathrm{s}$ work status and community-level characteristics indicative of availability of material resources and opportunities have significant effect on the timing of transition to adulthood mainly through longer period of education.
\end{abstract}

Key Words: Early life transition, life course trajectories, family disruption, social capital, community effects 
Zenaida R. Ravanera, Fernando Rajulton and Thomas K. Burch

\section{Résumé}

Cet article examine l'incidence de la transformation familiale et des caractéristiques communautaires sur le moment et l'enchaînement des transitions faites en bas âge des Canadiens nés entre 1971 et 1975 . En se servant des techniques d'analyse historiques, le fait d'avoir terminé ses études, de commencer un travail normal et de quitter la maison y sont examinés au moyen d'un ensemble de données réunissant les données de l'Enquête sociale générale sur la famille de 1995 avec les données provenant de secteurs de dénombrement du recensement de 1996. Les résultats révèlent que le démembrement d'une famille présente une incidence négative sur le passage à l'âge adulte. De plus, si la mère travaille et les caractéristiques de nature communautaire manifestant l'existence de moyens matériels et d'occasions ont un effet considérable sur le moment du passage à l'âge adulte essentiellement par des périodes d'éducation plus longues.

Mots-clés : transitions faites en bas âge, trajectoire de vie, démembrement de la famille, capital social, effets sur la communauté

\section{Introduction}

As in several Western countries, Canadians born from the mid 1960s experience transition to adulthood at later ages than the preceding cohorts (Furstenberg, 2002 and articles therein). They stay in schools longer pursuing post-secondaryeducation and enter the work force later (Fussell, 2002; Ravanera, Rajulton, and Burch, 1998; Ravanera et al, 2002). A consequenceof this is a longer stay in parental homes and delayed family formation either through cohabitationor marriage (Boyd and Norris, 1999; Lapierre-Adamcyk, Le Bourdais, and Lehrhaupt, 1995; Ravanera, Rajulton, and Burch, 1995, 1998; Ravanera et al. 2002). However, these general trends toward older ages at transitions to adulthood mask differences within cohorts influenced by several factors including the environmentand individual and parental characteristics (Shanahan, 2000; Booth, Crouter, and Shanahan, 1999 and articles therein).

This paper examines the effects of family transformation in Canada, in particular, marital dissolution and mother's work status, on the timing and sequence of events associated with transition to adulthood namely, school completion, start of regular work and leaving the parental home. In addition, the effects of community characteristics on the timing of these transitions are explored using a data set that merged individual- and community-level variables.

The paper consists of five parts: The first reviews relevant literature, the second discusses data and methodology, and the third and fourth present the results for community effects and results for family disruption and mother's work status. The last part highlights significant findings and their implications. 
Early Life Transitions of Canadian Youth:

Effects of Family Transformations and Community Characteristiics

\section{Literature Review:}

\section{Family Transformation and Early Life Transitions}

Families in Canada, like in many other Western countries, have significantly changed in the last half of the $20^{\text {th }}$ century. The high rates of separation and divorce, births within cohabiting unions that subsequently end in separation, and increase in non-marital births have meant that a great proportion of young adults in the 1990s have lived in non-intact families (Beaujot and Ravanera, 2001). Marcil-Gratton, Le Bourdais, and Lapierre-Adamcyk (2000) estimate from data collected through the 1994-95 National Longitudinal Survey of Children and Youth that 25\% of Canadians born in 1961-63 have experienced living in nonintact families by age 20. This trend has been increasing such that among the 198384 birth cohorts, $25 \%$ have lived in non-intact families by age 10 .

That family disruption has negative impact on youth outcome has been documented in studies done in the United States, Great Britain, and Canada. For instance, compared to children from intact families, children of divorced or separated parents are more likely to marry at younger age, to cohabit, to have premarital births, and to end their own marriage in divorce (Cherlin, Kiernan, and Chase-Lansdale, 1995; Kiernan and Cherlin, 1998; McLanahan and Bumpass, 1988; Le Bourdais and Marcil-Gratton,1998). Of greater relevance to this study are findings on the impact of family structures on earlier life transitions of school completion, entering into regular employment, and leaving the parental home. In Great Britain, these early life events were experienced at younger ages by children of families that experienced marital breakdown (Kiernan, 1992). In the United States, young adults who did not grow up with both biological parents were more likely to drop out or fail to graduate from high school (McLanahan and Sandefur, 1994; Musick and Bumpass, 1999). And, in both Canada and the United States, children of separated or divorced parents tend to leave home earlier (Aquilino, 1990; Zhao et al., 1995; Mitchell et al., 1989). Transitions at younger ages are seen to have consequences for the future of young adults in terms of their careers, incomes, and opportunities as precipitate transition to adulthood may curtail the acquisition of resources, abilities and experience needed by the young to successfully assume their adult roles (Kiernan, 1992; Aquilino, 1999).

The family structure's effect on the sequence of transitions has not been as widely studied as its effect on timing. Canadian studies on the sequences of transitions in early life have shown changes over cohorts but variations within cohorts have not been examined (Ravanera, Rajulton, and Burch, 1998; Ravanera et al, 2002).

However, studies in the United States show that ordering of transitions does vary within cohorts particularly by social class (Marini, 1984a; Hogan, 1981; Hogan and Astone, 1986). Young adults from higher social class are more likely to follow normative sequence (completing their schooling before marrying, for example) and 
Zenaida R. Ravanera, Fernando Rajulton and Thomas K. Burch

consequently less likely to experience in later life negative consequences such as marital instability (Hogan, 1980; Hogan and Astone, 1986, but see Marini, 1984b).

Another significant family change in Canada is the dramatic increase in the labour force participation of women, particularly of married women. The participation rate of married women aged 34 to 44 , for example, increased from $25 \%$ in 1961 to almost 80\% in 1991 (Beaujot, 1995). Women=s participation in the labour force could reduce parental investment of time on children with consequent effect felt in young adulthood. Finding time for children has become more difficult as parents grapple to balance the demands of the family and the workforce (Presser, 1989). And women $=\mathrm{s}$ employment, in addition to family dissolution, is seen to reduce the social capital investment on children (Coleman, 1990). Contrary to these expectations, however, Bianchi (2000) points out that women=s employment outside the home has not reduced maternal investment of time on children, most likely because of lower fertility, but also because mothers may have been more successful in preserving their time with children even as they get more involved in the work force. And, unlike marital dissolution, women's employment brings in more financial resources and consequently greater material investment on children.

This study examines the impact of the two significant changes that have transformed Canadian families - family dissolution and mother=s employment on the timing and sequences of early life transitions of young adults with the expectation that children from intact families and children of working mothers would make the transition to adulthood at older ages and would follow a sequence of transition that reflects greater parental support.

\section{Community Characteristics and Early Life Transitions}

Apart from individual and family characteristics, community characteristics also have effects on transition to adulthood. Availability of opportunities in communities has bearing on events experienced by young adults (Hogan, 1981). While Canadian education from elementary to post-secondary is mainly publicly funded, facilities do differ by location and size of communities, and thus can be source of differentials in access to education, and subsequently in work entry and leaving the parental home. The better the access to higher education, the longer will be the stay in school. In addition, availability of work and housing facilitiesvary by communities, both of which could lower the ages of transition.

Besides material resources and opportunities, community social capital is thought to be important for the outcome of children and youth. Coleman (1990) adds social capital to the economic concepts of financial and human capital and refers to it as social relations that "inhere in family relations and in community organization and 
Early Life Transitions of Canadian Youth: Effects of Family Transformations and Community Characteristiics

that are useful for the cognitive or social development of a child or young person" (p. 300) ${ }^{1}$. This definition implies that social capital exists both as family and community attributes. As a family attribute, social capital has been measured in terms of presence of both parents in the home, the number of siblings, and the interests of parents' on children's education (McLanahan and Sandefur, 1994; Coleman, 1988; Hagan, MacMillan, and Wheaton, 1996; Mitchell, 1994). As a community characteristic, social capital has been mainly measured indirectly, for example, by the number of school changes experiencedby a child because of family moves (Coleman, 1988), or by family migration status (Hagan, MacMillan, and Wheaton, 1996). McLanahanand Sandefur (1994) argue that social capital of single parents is lower because of more frequent change of residences that lead to fewer ties to other adults in the community. These imply that apart from family social capital there is a community social capital, in particular, community social bonds and controls that could positively influence youth's outcome and could compensate for lack of social capital within the family (Coleman, 1988; Portes, 1998; Mitchell, 1994). In this study, rather than measure community social capital indirectly, we explore the use of community characteristics as indicators of social capital. Like family social capital, we expect that community social capital would have positive influence on youth's early life transitions.

While community characteristics may have important impact on the early life transition of the youth, examination of this in Canada has not previously been possible, mainly because data were not available or not available in the proper form. A number of surveys on the family (such as the General Social Surveys and Family History Survey) have gathered retrospective data on various life course events and on characteristics of individuals and their parents, but they generally do not collect data on communities. The recent interest on social cohesion in Canada has provided an opportunity to examine the effects of community traits on individual behaviour. At our request, Statistics Canada merged community descriptors derived from the 1996 Census to various General Social Surveys, one of which is the 1995 General Social Survey on the Family. This paper takes advantage of the community data thus made available to explore the effects of community backgrounds, in particular, the community opportunity structures and social capital, on the timing of early life transitions of young Canadians.

\section{Data and Methodology}

\section{The 1995 General Social Survey}

The 1995 General Social Survey on the Family gathered data on the month and year of experiencing a number of events from early to late life of Canadians aged 15 and older. The survey covered a probability sample of 10750 respondents from all of Canada except the Yukon and Northwest Territories, and full time residents of institutions. However, this analysis focuses only on the 785 respondents who 
Zenaida R. Ravanera, Fernando Rajulton and Thomas K. Burch

were aged 20-24 as of survey date, that is, those born from 1971 to 1975 , for the following reasons: (a) In comparison to the older cohorts, a greater number in this cohort would have been born to parents who went through family changes; that is, family dissolution or mother $=\mathrm{s}$ entry into the labour force. (b) Unlike the youngest cohort (15-19 age group), a substantial number of those aged 20-24 would have already experienced the early life events of interest here. And, (c) data on communities were derived from the 1996 census, and therefore, analysis needs to be done for the cohort whose members would have experienced the events around the period as close to 1996 as possible ${ }^{3}$.

Confining our analysis to those aged 20-24 makes tenable the assumption that the later the transition to adulthood, the more favourable the situation of the young. A normative institutional expectation is completion of secondary education by around 17 or 18 , and college or university educationfrom about 20 to 22 years old. Thus, completion of schooling at say, 18 or 19 would mean that education would not have gone much beyond secondary education, and start of work at about the same age would most likely mean working at jobs that do not require much skill or training. Needless to say, completion of schooling at even younger ages, say, 15 or 16 would be a poor start indeed to a young person's life course.

\section{Statistical Techniques of Analysis}

This study uses three techniques of event history analysis: (a) survival or life table analysis, (b) hazard models of analysis, and (c) a state-space analysis of sequences. Life tables are prepared for each event by categories of family and community variables to obtain unbiased parameterestimates of timing of transitions. While life table analysis provides a good way of viewing differences in timing among subgroups, it essentially provides 'gross- comparison that does not control for the effects of other variables. To obtain the 'net- effects on timing, a multivariate analysis is done through proportional hazards models ${ }^{4}$. In particular, school completion, start of regular work, and home-leaving are used as dependent variables in Cox regression with family and community characteristics (indicators of which are described below) as independent variables controlling for a number of individual-level variables. SPSS is used for both survival and hazards models of analysis. Weighted cases are used for the survival analysis but not for the Cox regression in hazards analysisbecause SPSS does not allow for the use of fractional weights 5 .

The sequences of events are examined through a state-space approach in which each event - school completion, start of regular work, or leaving the parental home - is considered a $>$ state $=$ that is entered and left at certain time, and assumes that past history matters in the order of experiencing the events. This method of analysis is basically similar to multiple decrement life tables. In this study, sequence analysis is done on weighted data for categories of family variables and uses the nonMarkov technique of LIFEHIST, a computer software program for life history 
Early Life Transitions of Canadian Youth: Effects of Family Transformations and Community Characteristiics

analysis. (For more details on state-space approach and LIFEHIST see Rajulton, 2001).

\section{Measures of Community and Family Variables}

Communities in this study are the census enumeration areas of residence of the respondents. A number of indicators from the 1996 census of Canada were derived and appended to the 1995 General Social Survey. A limitation of community data derived from census enumeration area is that these are based on geographiclocation that only roughly approximates an individual's 'true community', a social construct that could differ even for individuals living in the same neighbourhood. It is difficult, if not impossible, to determine the 'true community' and measure its characteristics for each respondent of a national survey. In spite of this limitation however, previous studies using a merged census and survey data set (the 1998 General Social Survey on Time Use merged with the 1996 census data for enumeration areas, for example) proved to be useful and provided interesting results of community effects on individual behaviour (see Ravanera, Rajulton, and Turcotte, forthcoming; Ravanera and Rajulton, 2001). Another limitation of the data is that only about seventy-five percent of the respondents were successfully linked to their census enumeration areas of residence. Statistics Canada has not provided us the reason for this failure but we surmise that these respondents with missing data may have moved between the 1995 survey and the 1996 census. As the number of these cases is appreciable, we have included them in the analysis clearly identified as belonging to 'missing' category.

From an initial exploration to find out which of the several community variables available from the merged data set have statistical relation to the timing of transitions, four were selected for analysis, namely (a) type and size of area in which the community is located, (b) percent unemployed, (c) percent immigrant; (d) percent separated or divorced. The first two variables are meant to capture the opportunities or lack thereof in the communities. The inclusion of size and type of area - categorized into (i) rural; (ii) urban with less than 100,000 population; and (iii) urban with greater than 100,000 population - assumes that urban areas are more likely to have more facilitiesfor higher education, greater work opportunities, and more housing available to the young for independent living. The percent unemployed in a given area measures affluence, and availability of resources and opportunities in the community. The size and type of area refers to the larger environment, whereas the percent unemployed refers specifically to enumeration areas.

The percent immigrant and percent separated or divorced are used as indicators of community social capital; that is, the lower the percent immigrants or percent separated or divorced, the stronger the social bond in the community. This assumes that mobility discourages development of strong ties; that homogeneity of values contributes to closer bonds; and adherence to traditional values, 
Zenaida R. Ravanera, Fernando Rajulton and Thomas K. Burch

particularly of family values, provides supportive atmosphere to the youth. We are not aware of other studies that have used these variables as indicators of community social capital, however, in our study of youth societal integration, we found a negative relationship between these two community variables and sense of belonging; that is, the lower the percent immigrant or percent separated or divorced, the stronger is the sense of belonging to the community (Ravanera, Rajulton, and Turcotte, forthcoming).

Two family variables are included in the analysis to capture the effects of family changes, namely, the mother=s work status when the respondent was growing up, and whether or not a family disruption occurred in his/her childhood. The first variable was obtained from the question on whether the mother worked mainly fulltime, mainly part-time, or did not work during the respondent=s childhood (that is, from age 0 to 15$)$. The second variable is implied from the answer to the question on whether or not the respondent lived with both parents until the age of 15. To control for the effect of family social status, mother=s education is included among the control variables together with sex, marital status, first language, immigration status, and region of residence, all of which were found to have impact on early life events in previous studies (Zhao et al, 1995, Mitchell et al, 1989; Lapierre-Adamcyk et al., 1995). In addition, respondent's education is also used as a control variable in the analysis of timing of start of regular work and home-leaving but not for timing of school completion. This is because the level of respondent $=\mathrm{s}$ education is virtually synonymous with measure of timing of school completion; that is, the longer the stay in school, the higher is the level of education.

\section{Results: Community Variables}

\section{Opportunity Structures Do Matter but Mainly for Schooling}

That community resources and opportunities in the larger environment do matter could be gleaned from the median ages of experiencingthe events (Table 1) but, the magnitude and patterns of differences are clear mainly for the timing of end of schooling. Young Canadians end their schooling at 19.7 years in the rural area whereas those in the urban area ${ }^{6}$ with population of 100,000 or more do so at 22.3 years, a difference of about two and a half years. The differential by percent unemployed is in the same direction; that is, in communities with low unemployment, young Canadians end their schooling at about 22 years of age, one and a half years later than those living in communities with high unemployment. This is contrary to the common assumption that many young people stay in school when unemployment rates are high, which may be true over time, but as these data suggest, may not be true in areal cross-section or across social classes. 
Early Life Transitions of Canadian Youth: Effects of Family Transitions and Community Characteristics

Table 1

Life Table Median Ages at School Completion, Start of Regular Work and Home-Leaving by Community and Family Variables,

Canadians Aged 20-24, 1995 General Social Survey

\begin{tabular}{|c|c|c|c|c|}
\hline Variable & $\begin{array}{c}\text { Weighted } \\
\mathbf{N}\end{array}$ & $\begin{array}{c}\text { School } \\
\text { Completion }\end{array}$ & $\begin{array}{l}\text { Start of } \\
\text { Work }\end{array}$ & $\begin{array}{l}\text { Home- } \\
\text { Leaving }\end{array}$ \\
\hline \multicolumn{5}{|l|}{ Community Variables } \\
\hline \multicolumn{5}{|l|}{ Type and Size of Area } \\
\hline Rural & 116 & 19.7 & 20.1 & 22.9 \\
\hline Urban $<100,000$ & 136 & 20.7 & 20.1 & 21.3 \\
\hline Urban 100,000 and over & 347 & 22.3 & 21.8 & 22.6 \\
\hline \multicolumn{5}{|l|}{ Percent Unemployed } \\
\hline $0-2 \%$ & 161 & 22.0 & 20.6 & 22.5 \\
\hline $3-5 \%$ & 222 & 22.1 & 21.8 & 22.8 \\
\hline $6 \%$ and Over & 248 & 20.5 & 20.2 & 22.1 \\
\hline \multicolumn{5}{|l|}{ Percent of Immigrants } \\
\hline $0-5 \%$ & 206 & 20.5 & 20.4 & 22.1 \\
\hline $6-14 \%$ & 152 & 21.4 & 20.4 & 22.5 \\
\hline $15 \%$ and over & 274 & 22.2 & 21.3 & 22.5 \\
\hline \multicolumn{5}{|l|}{ Percent Separated/Divorced } \\
\hline $0-3 \%$ & 152 & 21.6 & 22.0 & 22.9 \\
\hline $4-8 \%$ & 319 & 21.0 & 20.0 & 22.6 \\
\hline $9 \%$ and over & 161 & 22.0 & 21.5 & 21.2 \\
\hline Missing & 187 & 22.3 & 22.0 & 22.3 \\
\hline \multicolumn{5}{|l|}{ Family-Related Variables } \\
\hline \multicolumn{5}{|l|}{ Mother's Work Status } \\
\hline Mainly Full-Time & 320 & 22.2 & 21.8 & 22.4 \\
\hline Mainly Part-Time & 193 & 21.2 & 20.6 & 23.0 \\
\hline Never Worked & 294 & 20.9 & 20.5 & 21.7 \\
\hline \multicolumn{5}{|l|}{ Living Arrangement Till Age 15} \\
\hline Lived with Both Parents & 626 & 22.0 & 21.5 & 22.6 \\
\hline Did not Live with Both Parents & 151 & 21.0 & 19.2 & 20.5 \\
\hline
\end{tabular}


Zenaida R. Ravanera, Fernando Rajulton and Thomas K. Burch

The type and size of area seems to have the same effect on the start of regular work as it has on end of schooling though smaller in magnitude (a difference of only 1.5 for work start as against 2.5 years for schooling) but its effect on home-leaving is not clear. As for percent unemployed, it has no effect on home-leaving and an unclear effect on start of work.

To get at the net effects of these variables, hazard models of analysis were done, results of which are presented in Table 2 that shows the coefficients and their exponentials obtained from Cox regression procedures. A positive coefficient (or an exponential greater than 1) indicates that those belonging to the category have a higher risk (and therefore, a younger age) at experiencing the event than those belonging to the reference category. A negative coefficient (or exponential less than 1) denotes lower risk (and therefore, later age) at experiencing the event.

(Table 2 about here)

The hazard models confirm that the location and size of area and percent unemployed do have an effect on end of schooling but have no effect on start of regular work and home-leaving. An exception is the significantly higher risk of home-leaving among those residing in small urban area. This may be an indication of greater availability in small urban areas of affordable rental accommodations, which may be few in rural areas and expensive in large urban areas. The effects of type and size of area and percent unemployed on end of schooling are roughly linear; that is, the urban area with less than 100,000 population has negative effect but not significantly different from the reference category, while that of the urban area has negative and highly significant effect. This means that everything else being equal, those in the urban area are more likely to complete their schooling at older ages than those living in the rural areas, and that this advantage is greater the bigger the urban area. Similarly, the positive coefficient of 3-5\% unemployed is not significant whereas that of $6 \%$ or more unemployed is positive and significant, which means, that the higher the unemployed in the community, the greater the likelihood of ending schooling at younger ages.

The survival function of school completion (Figure 1) by type and size of area gives a glimpse of what could be happening: the gap between the rural and the urban areas is discernible even at age 15 but the gap between the small and big urban areas appear only at about 17 or 18 , the age when tertiary education begins. By about age 22, there is no longer a gap between the rural and small urban areas but the proportion still in school continues to be higher for those in big urban areas. All these seem to point to the advantage in terms of resources for higher education in big urban areas. Another point shown in Figure 1 is that the life table survival function of the group with missing community level variable is virtually the same as that of the survival function for the big urban area. In the hazard model, this effect is captured as well by the negative coefficient of the $>$ missing= category in the percent unemployed variable (Table 2), which indicates that those belonging to this group have the lowest risk of ending schooling, and therefore, 
Early Life Transitions of Canadian Youth: Effects of Family Transitions and Community Characteristics

Table 2

Cox Regression Coefficients and Exponentials: School Completion, Work Start, and Home-Leaving, Canadians Aged 20-24, 1995 General Social Survey

\begin{tabular}{|c|c|c|c|c|c|c|}
\hline \multirow[b]{2}{*}{ Community Variables } & \multicolumn{2}{|c|}{ School Completion } & \multicolumn{2}{|c|}{ Work Start } & \multicolumn{2}{|c|}{ Home-Leaving } \\
\hline & B Coeff & $\operatorname{Exp}(B)$ & B Coeff & $\operatorname{Exp}(B)$ & B Coeff & $\operatorname{Exp}(B)$ \\
\hline \multicolumn{7}{|l|}{ Type and Size of Area } \\
\hline Rural $®$ & 0.00 & 1.00 & 0.00 & 1.00 & 0.00 & 1.00 \\
\hline Urban $<100,000$ & -0.10 & 0.90 & 0.11 & 1.11 & $0.30 *$ & 1.35 \\
\hline Urban 100,000 and over & $-0.60 * * *$ & 0.55 & -0.04 & 0.97 & 0.04 & 1.04 \\
\hline \multicolumn{7}{|l|}{ Percent Unemployed } \\
\hline $0-2 \%(\mathbb{R}$ & 0.00 & 1.00 & 0.00 & 1.00 & 0.00 & 1.00 \\
\hline $3-5 \%$ & 0.16 & 1.17 & -0.07 & 0.93 & 0.02 & 1.02 \\
\hline $6 \%$ and Over & $0.33 * *$ & 1.39 & 0.10 & 1.11 & -0.01 & 0.99 \\
\hline Missing & $-0.46 *$ & 0.63 & -0.32 & 0.73 & -0.07 & 0.93 \\
\hline \multicolumn{7}{|l|}{ Percent Immigrants } \\
\hline $0-5 \% ®$ & 0.00 & 1.00 & 0.00 & 1.00 & 0.00 & 1.00 \\
\hline $6-14 \%$ & 0.14 & 1.16 & 0.21 & 1.23 & 0.11 & 1.12 \\
\hline $15 \%$ and over & 0.17 & 1.19 & 0.15 & 1.16 & 0.00 & 1.00 \\
\hline \multicolumn{7}{|l|}{ Percent Separated/Divorced } \\
\hline $0-3 \% ®$ & 0.00 & 1.00 & 0.00 & 1.00 & 0.00 & 1.00 \\
\hline $4-8 \%$ & $-0.26 *$ & 0.77 & 0.18 & 1.20 & -0.05 & 0.95 \\
\hline $9 \%$ and over & $-0.43 * *$ & 0.65 & -0.15 & 0.86 & 0.17 & 1.18 \\
\hline \multicolumn{7}{|l|}{ Family of Origin Variables } \\
\hline \multicolumn{7}{|l|}{ Mother's Work Status } \\
\hline Mainly Full-Time & $-0.28 * *$ & 0.75 & -0.02 & 0.98 & -0.03 & 0.97 \\
\hline Mainly Part-Time & -0.11 & 0.90 & -0.02 & 0.98 & $-0.24 *$ & 0.79 \\
\hline Never Worked ${ }^{\circledR}$ & 0.00 & 1.00 & 0.00 & 1.00 & 0.00 & 1.00 \\
\hline \multicolumn{7}{|l|}{ Living Arrangement Till Age 15} \\
\hline Lived with Both Parents & -0.17 & 0.84 & $-0.55 * * *$ & 0.58 & $-0.33 * * *$ & 0.72 \\
\hline Did not Live with Both Parents ${ }^{\circledR}$ & 0.00 & 1.00 & 0.00 & 1.00 & 0.00 & 1.00 \\
\hline \multicolumn{7}{|l|}{ Sex } \\
\hline Male & 0.03 & 1.04 & $0.34 * * *$ & 1.40 & $-0.28 * * *$ & 0.75 \\
\hline Female ${ }^{\circledR}$ & 0.00 & 1.00 & 0.00 & 1.00 & 0.00 & 1.00 \\
\hline \multicolumn{7}{|l|}{ Mother's Education } \\
\hline Elementary ${ }^{\circledR}$ & 0.00 & 1.00 & 0.00 & 1.00 & 0.00 & 1.00 \\
\hline High School & $-0.33 * *$ & 0.72 & $-0.32 * *$ & 0.72 & -0.03 & 0.97 \\
\hline College & $-0.66 * * *$ & 0.52 & $-0.59 * * *$ & 0.56 & 0.13 & 1.14 \\
\hline Not Known & -0.19 & 0.82 & -0.30 & 0.74 & -0.11 & 0.90 \\
\hline \multicolumn{7}{|l|}{ Respondent's Education } \\
\hline Some High School or lower & & & $0.32 * *$ & 1.38 & $0.88 * * *$ & 2.41 \\
\hline High School Graduate & & & $0.56 * * *$ & 1.74 & 0.13 & 1.14 \\
\hline Some College & & & -0.08 & 0.93 & 0.18 & 1.20 \\
\hline College/University Graduate ${ }^{\circledR}$ & & & 0.00 & 1.00 & 0.00 & 1.00 \\
\hline
\end{tabular}


Zenaida R. Ravanera, Fernando Rajulton and Thomas K. Burch

Table 2 (Cont'd)

Cox Regression Coefficients and Exponentials: School Completion, Work Start, and Home-Leaving of Canadian Aged 20-24, 1995 General Social Survey

\begin{tabular}{|c|c|c|c|c|c|c|}
\hline \multirow[b]{2}{*}{ Control Variables } & \multicolumn{2}{|c|}{ School Completion } & \multicolumn{2}{|c|}{ Work Start } & \multicolumn{2}{|c|}{ Home-Leaving } \\
\hline & B Coeff & $\operatorname{Exp}(B)$ & B Coeff & $\operatorname{Exp}(B)$ & B Coeff & $\operatorname{Exp}(B)$ \\
\hline \multicolumn{7}{|l|}{ Sex } \\
\hline Male & 0.03 & 1.04 & $0.34 * * *$ & 1.40 & $-0.28 * * *$ & 0.75 \\
\hline Female ${ }^{\circledR}$ & 0.00 & 1.00 & 0.00 & 1.00 & 0.00 & 1.00 \\
\hline \multicolumn{7}{|l|}{ Mother's Education } \\
\hline Elementary ${ }^{\circledR}$ & 0.00 & 1.00 & 0.00 & 1.00 & 0.00 & 1.00 \\
\hline High School & $-0.33 * *$ & 0.72 & $-0.32 * *$ & 0.72 & -0.03 & 0.97 \\
\hline College & $-0.66 * * *$ & 0.52 & $-0.59 * * *$ & 0.56 & 0.13 & 1.14 \\
\hline Not Known & -0.19 & 0.82 & -0.30 & 0.74 & -0.11 & 0.90 \\
\hline \multicolumn{7}{|l|}{ Respondent's Education } \\
\hline Some High School or lower & & & $0.32 * *$ & 1.38 & $0.88 * * *$ & 2.41 \\
\hline High School Graduate & & & $0.56 * * *$ & 1.74 & 0.13 & 1.14 \\
\hline Some College & & & -0.08 & 0.93 & 0.18 & 1.20 \\
\hline College/University Graduate $\mathbb{}(\mathbb{}$ & & & 0.00 & 1.00 & 0.00 & 1.00 \\
\hline \multicolumn{7}{|l|}{ Marital Status } \\
\hline Single ${ }^{\circledR}$ & 0.00 & 1.00 & 0.00 & 1.00 & 0.00 & 1.00 \\
\hline Common-Law & $0.43 * * *$ & 1.54 & $0.49 * * *$ & 1.64 & $0.86 * * *$ & 2.37 \\
\hline Married & $0.34 * *$ & 1.41 & $0.56 * * *$ & 1.75 & $1.12 * * *$ & 3.07 \\
\hline Widowed-Divorced-Separated & $1.02 * *$ & 2.76 & 0.57 & 1.77 & $0.77 *$ & 2.17 \\
\hline \multicolumn{7}{|l|}{ First Language } \\
\hline English & $0.37 *$ & 1.45 & $0.40 *$ & 1.49 & 0.13 & 1.14 \\
\hline French & $0.68 * *$ & 1.98 & $0.70 * * *$ & 2.02 & 0.08 & 1.09 \\
\hline Other $\mathbb{R}$ & 0.00 & 1.00 & 0.00 & 1.00 & 0.00 & 1.00 \\
\hline \multicolumn{7}{|l|}{ Immigration Status } \\
\hline Born in Canada & -0.16 & 0.85 & 0.19 & 1.21 & 0.17 & 1.18 \\
\hline Born Outside Canada ${ }^{\circledR}$ & 0.00 & 1.00 & 0.00 & 1.00 & 0.00 & 1.00 \\
\hline \multicolumn{7}{|l|}{ Region of Residence } \\
\hline Atlantic & $-0.61 * * *$ & 0.54 & $-0.80 * * *$ & 0.45 & $-0.55 * * *$ & 0.58 \\
\hline Quebec & $-0.68 * * *$ & 0.51 & $-0.78 * * *$ & 0.46 & -0.22 & 0.80 \\
\hline Ontario & $-0.33 *$ & 0.72 & $-0.74 * * *$ & 0.48 & $-0.63 * * *$ & 0.53 \\
\hline Prairies & $-0.28 *$ & 0.76 & $-0.35 * *$ & 0.70 & -0.25 & 0.78 \\
\hline British Columbia ${ }^{\circledR}$ & 0.00 & 1.00 & 0.00 & 1.00 & 0.00 & 1.00 \\
\hline Total Number of Cases & 704 & & 710 & & 715 & \\
\hline Number Censored & 245 & & 234 & & 240 & \\
\hline
\end{tabular}

Levels of Significance: *** $1 \%, * * 5 \%, 10 \%$ 
Early Life Transitions of Canadian Youth: Effects of Family Transformations and Community Characteristiics

complete their schooling at older ages ${ }^{7}$. This probably means that those whose survey records could not be linked with their census data are those who moved residence between 1995 and 1996 either within the big urban area or possibly point to a selective migration; that is, those with missing community variables are those from the rural and small urban areas who may have moved to big urban areas for higher education. Thus, the availability of resources for post-secondary education in big urban areas not only provides opportunities for the non-movers but also acts as a pull factor for migrants desirous of obtaining higher education.

\section{Unclear Effects of Community Social Capital}

The life table median ages in Table 1 show that, contrary to our expectation, the higher the percent immigrant in communities, the older are the ages at school completion and start of regular work. However, the hazard models (Table 2) show that percent immigrant no longer has any significanteffect when other variables are controlled for. Young people in places with the highest percent separated or divorced end their schooling at older ages but start regular work and leave parental homes at younger ages (Table 1). The effect persists for end of schooling but disappears for start of regular work and home-leaving when all other variables are controlled for (Table 2).

The results presented for these two variables, percent immigrant and percent separated or divorced, do not seem to provide evidence that community social capital have positive influence on the experience of early life transitions of young Canadians. As previous studies that have measured community social capital indirectly through the number of family moves (Coleman, 1988) or migration status (Hagan, MacMillan, and Wheaton, 1996) have shown positive effects on schooling, it may well be too early to rule out the importance of community social capital. It is possible that their indirect measures do not in fact capture community social capital but are simply additional measures of family social capital, thereby pointing to the inadequacy of social capital theory. However, it could also be that our direct indicators derived for census enumeration areas inadequately measure social capital for relevant communities. Later research might need to deal with different spatial units or combinations thereof.

\section{Results: Family Variables}

\section{A Harder Life for Young Adults from Non-Intact Families}

Children who did not live with both parents until age 15 are likely to end school one year earlier, and start regular work and leave home two years earlier than children who did live with both parents (Table 1). Everything else being equal, 
Zenaida R. Ravanera, Fernando Rajulton and Thomas K. Burch

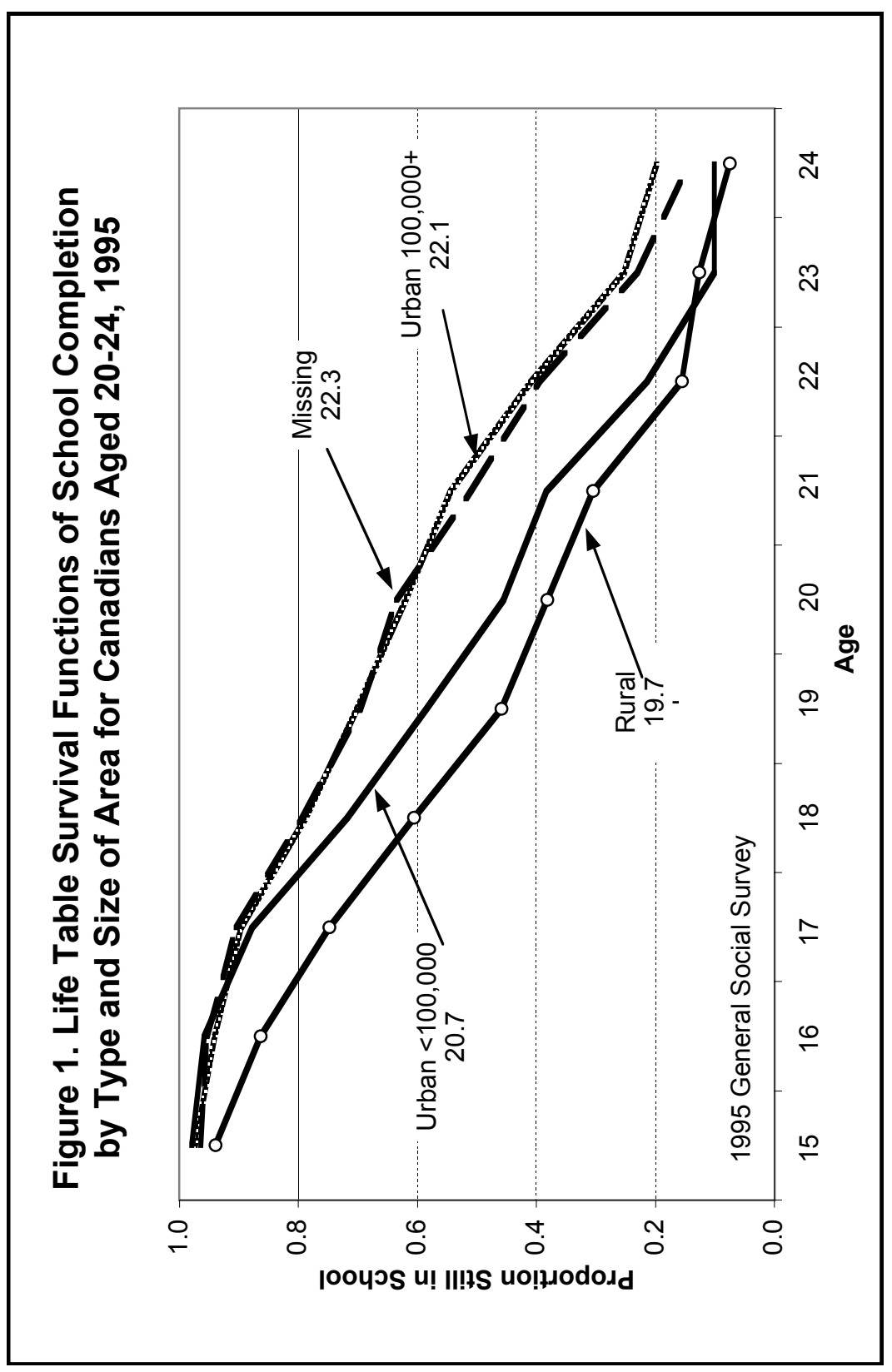


Early Life Transitions of Canadian Youth: Effects of Family Transformations and Community Characteristiics

children from intact families have significantlylower risks of starting regular work and leaving home (Table 2). The risk of ending schooling is also lower though not statistically significant. The differences between the two sub-groups are clearly seen in Figure 2: For school completion, the gap in the two groups appear only around the age when the children start to enter tertiary level of schooling or around age 18 and disappears altogether by around age 23. A somewhat similar pattern occurs for work start and home-leaving in that the proportion still not working or still living at home decreases more gradually for children of intact families but decreases more rapidly for those of non-intact families at around age 17 to 19 .

(Figure 2 about here)

The divergent pathways of these two groups of young adults can be seen in Table 3 . Those who lived with both parents until age 15 have higher probability of school completion as their first transition ( 0.31 for children from intact families as against 0.20 for children from non-intact families); while those who did not live with both parents have higher probabilities of starting regular work ( $0.42 \mathrm{vs} .0 .38)$ or leaving home (0.34 vs. 0.28). But, whatever is the first event experienced, young adults from intact families go through the transition at older ages than those from disrupted families; thus, for end of schooling, 20.1 years as against 19.4; for start of regular work, 18.7 vs. 17.7; and for home-leaving, 19.0 vs. 17.5 years.

(Table 3 about here)

Individuals go through second and third transitions by experiencing the other two events not undergone as the first transition. Multiplying the probability of the first with the second and the third transition probabilities provides a final probability of going through a certain trajectory. The probability of going through the predominant trajectory of work start - school completion - leaving home (path B1 in Table 3 ) is similar for both sub-groups (0.23 and 0.24$)$. However, the transition probability of school completion after start of work is higher among those from intact families $(0.71$ vs. 0.63$)$. The next most common trajectory is school completion - start of work - leaving home (path A1) with 0.18 and 0.17 probabilities for young adults from intact families and from non-intact families respectively. While these probabilities are almost equal, those who lived with both parents until age 15 have lower transition probabilities of starting regular work and leaving home.

Of those whose first transition is leaving the parental home, young adults who have lived with both parents until age 15 are more likely to leave home for schooling (leaving home - school completion - work start, path C1) with transition probability of 0.57 (as against 0.38 ). Those who have not lived with both parents are more likely to leave home to go for work (leaving home - work start - school completion, path $\mathrm{C} 2$ ), with a transition probability of 0.46 (as against 0.25 ).

One way of summing up these differences is that independence through work or home-leaving happens earlier among children of non-intact families, while those 
Figure 2

Life Table Survival Functions of School Completion, Start of Regular Work, and Home Leaving by Living Arrangement to Age 15,

Canadians Aged 20-24, 1995 General Social Survey
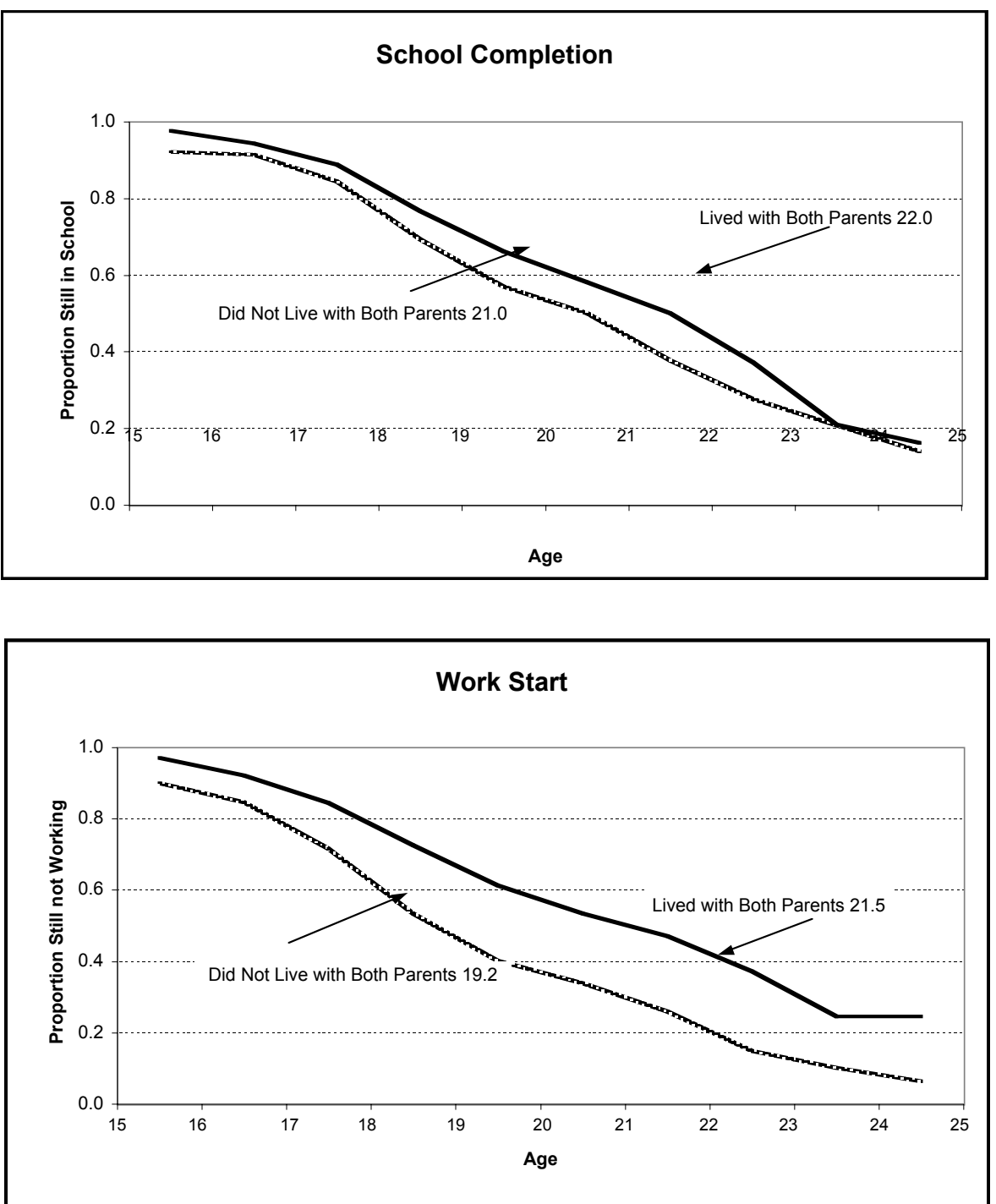
Early Life Transitions of Canadian Youth: Effects of Family Transitions and Community Characteristics

Figure 2

Life Table Survival Functions of School Completion, Start of Regular Work, and Home Leaving by Living Arrangement to Age 15,

Canadians Aged 20-24, 1995 General Social Survey

(Continued)

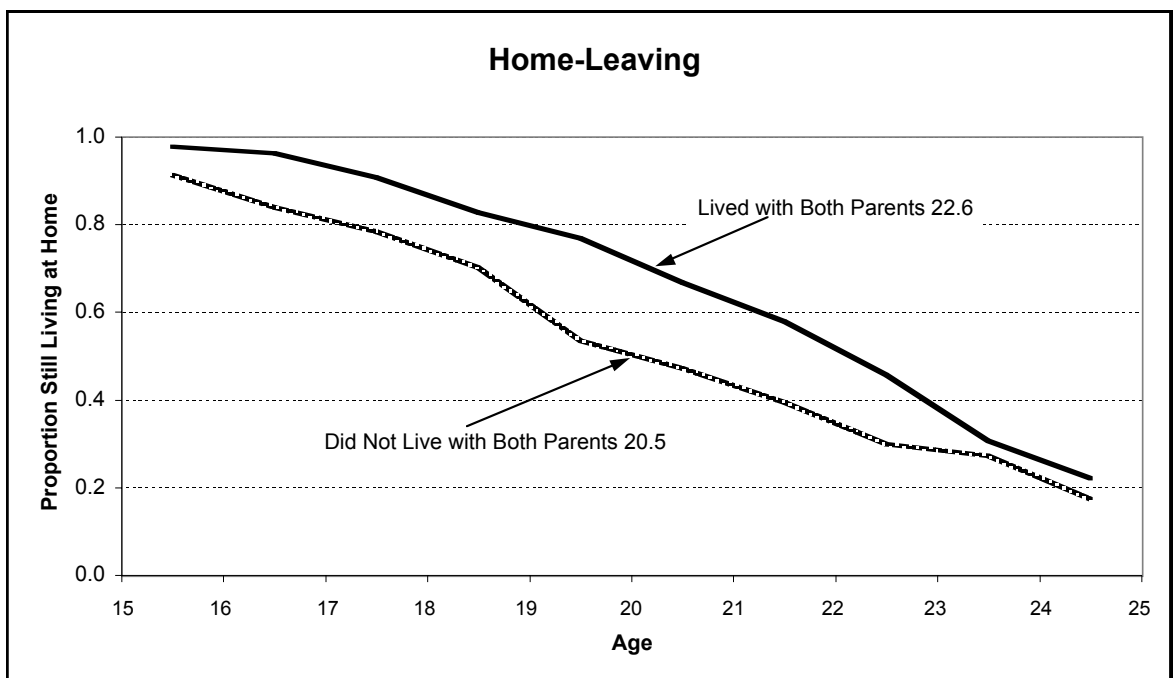


Zenaida R. Ravanera, Fernando Rajulton and Thomas K. Burch

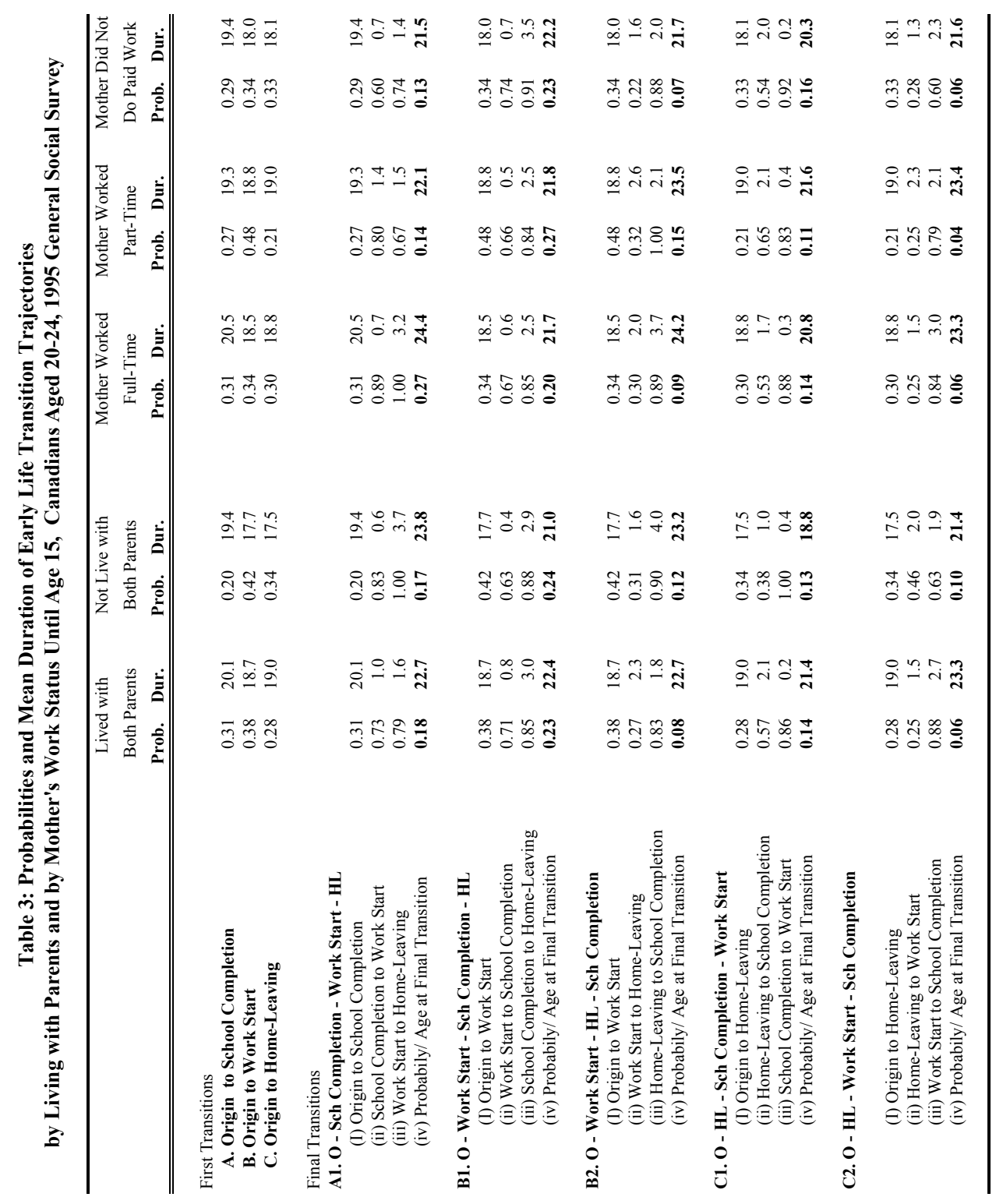


Early Life Transitions of Canadian Youth: Effects of Family Transformations and Community Characteristiics

from intact families continue to have parental support, particularly for education, until later ages. Becoming independent is not necessarily detrimental to young adults; however, a precipitate move toward independence could curtail the period for accumulating human capital. A simple cross-tabulation of the level of attained education and the current occupation of these young peoples shows that there are significantly greater proportions with high levels of education and occupation among those who have lived with both parents until age 15 .

It could be argued that the effect of marital dissolution on early life transition is due to lower income of non-intact families. While household income has not been controlled for in the analysis (due to problems with use of income data from the survey $^{8}$ ), mother $=\mathrm{s}$ education has been controlled for, which is correlated with household income. And, while the mother=s work status variable refers to the time when the children were growing up, it is very likely that current work status of mothers would be very similar, which could be another proxy for household income (see below). Therefore, if low financial or material investment is ruled out for this effect, then a possible explanation could be found in family social capital; that is, children in non-intact family may have a deficit social capital investment in the form of lower parental expectation, reduced parental supervision, or less dense social network.

\section{Working Mothers Bring Additional Resources}

Young adults whose mothers have worked away from home during their childhood end their schooling, start regular work, and leave home at older ages than those whose mothers did not. The median ages at school completion (22.2) and work start (21.8) are highest for those whose mothers worked mainly full time and lowest (20.9 for end of schooling, and 20.5 for work start) for those whose mothers never worked on paid jobs (Table 1). As for home-leaving, those whose mothers worked part time left home latest (23.0) and those whose mothers did not do paid work left the earliest (21.7).

These effects for school completion and for home-leaving continue to be significant after controlling for other variables, but disappear for start of regular work. In comparison to those whose mothers never worked, those whose mothers worked mainly full time have 0.25 lower risk of ending their schooling. And, those with mothers who worked part time have about 0.20 lower risk of leaving home (Table 2 ). In addition to bringing home financial resources, mothers who work part-time may still be able to do housework and be more available to provide companionship and emotional support to their children, thereby making the stay in parental homes more attractive to young adults. 
Zenaida R. Ravanera, Fernando Rajulton and Thomas K. Burch

The most likely trajectory for young adults whose mothers worked full time is the school completion - work start - leaving home path (A1) with a probability of 0.27 (Table 3). This path is followed with 0.14 probability among those whose mothers worked part time, and 0.13 for those whose mother's did not work. Not only the probabilities but also the timings of occurrences vary. Among those who followed this path, the age at completing the final transition is highest among those whose mothers worked full time (24.4 years) and lowest among those whose mothers did not work (21.5).

The trajectory most commonly followed by those whose mothers worked part-time and those whose mothers did not work is the work start - school completion leaving home path (B1) with 0.27 and 0.23 probabilities respectively. The probability among those whose mothers worked full time is also high at 0.20 . Another path that is differentiated by mother $=\mathrm{S}$ work status is the leaving home work start - school completion path (C2). Although the final probabilities are not too different by mother's work status, the probability of transition from work start to school completion is highest (0.84) among those whose mothers worked full time and lowest among those whose mothers never worked (0.60). The age at completion of the final transition is also higher among those whose mothers worked (about 23.3 years) than for those whose mothers did not (21.6).

These results show that mother=s work away from home may not be detrimental for youth outcome. Children of working mothers benefit through prolonged schooling into young adulthood most likely facilitated by the financial or material resources that working mothers bring to the household. Though working mothers may not have time to contribute to community social capital, for example, by volunteering, they may nevertheless provide social capital through higher expectations for their children, acting as role models particularly to daughters, and providing wider social network through their own work contacts.

\section{Conclusions}

Our analysis highlights the effects of family disruption and mother's work status on the timing and ordering of transitions to school completion, start of regular work, and leaving the parental home. We find that young adults who have lived with both parents until age 15 are more likely to start regular work and leave the parental home at older ages. The effect of mother's employment is similar in that the young are providedresources to ease the transition to adulthood mainly through higher education.

Young adults from intact families and from families with mothers who were employed are also more likely to follow trajectories that provide a higher probability of school completion. From the perspective of developing human capital with family support, a normatively expected sequence of transitions for a 
Early Life Transitions of Canadian Youth: Effects of Family Transformations and Community Characteristiics

young adult would be to finish schooling (preferably a college or university education) before starting regular work (in a job requiring advanced skills) and then leaving the parental home to live independently on one $=\mathrm{s}$ own. An equally desirable trajectory would be to leave home for higher education and then to start work after completion of schooling.

While we have assumed that the longer it takes before an event is experienced, the better it is for young adults, early work and home-leaving may be quite positive, particularly for someone learning a skilled trade or starting his/her own business. They can be, after all, indications of maturity, initiative, and independence (Mortimer, Harley, and Aronson, 1999). Also, these three transitions of school completion, start of regular work, and home-leaving can be placed in the wider context of later ones. For example, many university graduates are finishing school with large debts, such that commitment to marriage and family are difficult. By the same token, some young couples may have strong commitments to marriage and family, and arrange home-leavingand work accordingly. Thus, eventually, the evaluation of a transition as positive or negative depends on why it occurs.

The results of this study show that resources in the communities and the urban character of the area in which the communities are located contribute to the prolongation of schooling (and hence, to attainment of higher levels of education) of young adults. These seem to have an impact also on the timing of starting regular work though most likely mediated through education.

This study does not provide evidence of the impact of community social capital on early life transitions of young adults, however, because previous studies have found that it has positive influence on schooling (albeit with indirect measures using family-related variables), we do not rule out its importance. And, family social capital, as indicated by whether or not these young adults lived with both parents until age 15, does have an effect. These, taken together, highlight the need for more research to understand social capital and how it impacts on youth outcome. Despite the work of Coleman (1990) and Porter (1998) and empirical studies relating social capital to children and youth outcome, there is as yet no well developed theory of social capital (see endnote 1). Our attempt at measuring community social capital is only a small beginning aimed at understanding its relation to the three featured transitions.

While we have focused on family background and community characteristics, individual traits do affect early life transitions and we have included them in the analysis but mainly as control variables. One such variable, for example, is sex as earlier studies have shown differences in timing of transitions between men and women, which are also reflected in our results here - that is, young men start work earlier but leave home later. It would have been interesting to find out the differences in the trajectories by sex, however, the small number of cases did not allow such an analysis. 
It may be worth pondering on a few points from the results of the analysis. Given that community variables, particularly those indicative of opportunities, have effects on schooling rather than on work start, spending state resources for training and education may be a good way to positively influence the life courses of young adults. With skills developed, favourable transition to work would most likely follow.

Children of working mothers have distinct advantage, which points to imbalance in access to higher education. Any reduction in funding for post-secondary education that limits universal access may further exacerbate the differencesin early life transitions between those who have greater family resources through mother's involvement in paid work and those who do not have such additional resource.

Finally, non-material support or social capital investment on children and young adults is equally important as material or financial resources. Certainly, children's well-being should be one of the major considerations in couple's decision to separate. But, if separation has to happen for compelling reasons (for example, abusive relationship), supportive atmosphere should be provided such that young adults' accumulation of human capital is not precipitously curtailed.

\section{Acknowledgments}

This study is part of the project on Family Transformation and Social Cohesion funded throughCanada's Social Science and Humanities Research Council strategic grant program on the theme Social Cohesion in Globalizing Era. Some of the analyses were done at Statistics Canada's Research Data Centre. The authors thank the two anonymous reviewers who provided very useful suggestions.

\section{End Notes:}

1. In spite of this seemingly clear definition, social capital is an amorphous concept that has taken several meanings measured in different ways. While some forms of social capital that Coleman suggests such as obligations and expectations, and norms and sanctions signify that it is a group attribute, another form, authority relations can be an individual property. He says, for example, that when a number of individuals transfer rights of control of certain action to one person, that individual acquires "an extensive body of social capital ..." (Coleman, 1990: 311). Thus, some economists and demographers (Aston et al.1999, Glaeser, 2001) have argued that social capital is an attribute of an individual, while others, particularly political scientists (Putnam,2000) have taken it as an attribute of a group, such as a country. The concept of 
Early Life Transitions of Canadian Youth:

Effects of Family Transformations and Community Characteristics

social capital seems clearer when used as family attribute and applied to children and youth's outcome.

2. The questions asked on early life events were as follows:(i) School completion: What is the highest level of education you have attained? In what month and year did you complete your studies? (ii) First regular work: Have you ever worked at a job or business on a regular basis? By this I mean a full-time or part-time job which lasted six months or longer. In what year and month did you first start working on a regular basis? Exclude part-time employment while you were attending school full-time. (iii) Home-leaving: In what month and year did you last live with one or both of your parents (or parent substitutes)?

3. From a social capital or community support perspective, one might argue that survey data for this group should also be linked to earlier census data. For example, the 1991 community data would have been relevant to this cohort $=\mathrm{s}$ early high school experience and entry into the work force. Our request to Statistics Canada was, however, confined to the census conducted as near to the survey dates as possible.

4. While we have considered techniques more appropriate to multi-level analysis (mixed model using MLwin, for instance), we deemed it best to use Cox regression in as much as we do not actually have cluster data. That is, the community data we have were derived from the census and subsequently appended to each respondent previously selected through probability sampling that did not take communities into account.

5. Using another program (LIFEHIST) that handles weighting properly showed that results do not vary substantially. The test was done only for variables available from the public use micro-data file of the 1995 General Social Survey.

6 The phrase "those in urban areas" includes those that have grown up in such areas, but also those who migrated to such areas prior to the GSS survey date (residence of those migrating after survey date is apt to be 'missing,' as noted below). A proportion of those may have migrated as young adults, precisely to avail themselves of more favourable educational or work opportunities in larger cities.

7. There are no coefficient estimates for the $>$ missing= category in the other community level variablesas the same respondents have missing values for all the community level variables. The size and type of area variable has a few more missing cases, the non-significant coefficients for which are not shown on the table in order to avoid confusion with the >missing= category applicable for all community variables. 
Zenaida R. Ravanera, Fernando Rajulton and Thomas K. Burch

8. Many respondents were unable to provide information on household income. Personal income does not provide the total resources available to the young, particularly for those still living in parental households.

\section{References:}

Aquilino, W. S. 1990. "The Likelihood of Parent-Adult Child Coresidence: Effects of Family Structure and Parental Characteristics," Journal of Marriage and the Family 52: 405-419.

Aquilino, W. S. 1999. Rethinking the Young Adult Life Stage: Prolonged Dependency as an Adaptive Strategy, in A. Booth, A.C. Crouter, and M.J. Shanahan (eds) Transitions to Adulthood in a Changing Economy: No Work, No Family, No Future? Westport: Praeger. Pp. 168-175.

Astone, N.M., C.A. Nathanson, R. Schoen, and Y. J. Kim.(1999). "Family Demography, Social Theory, and Investment in Social Capital," Population and Development Review 25(1): 1-31.

Beaujot, R. 1995. Family Patterns at Mid-Life (Marriage, Parenting, and Working), in R. Beaujot, E. Gee, F. Rajulton, and Z. R. Ravanera, Family Over the Life Course. Statistics Canada Cat. 91-543E.

Beaujot, R. and Z. R. Ravanera.. 2001. An Interpretation of Family Change, With Implications for Social Cohesion. University of Western Ontario, Population Studies Center Discussion Paper 01-1.

Bianchi, S. M. 2000. "Maternal Employment and Time With Children: Dramatic Change or Surprising Continuity," Demography 37: 401-14.

Booth, A., A.C. Crouter, and M.J. Shanahan (eds). 1999. Transitions to Adulthood in a Changing Economy: No Work, No Family, No Future? Westport: Praeger.

Boyd, M. and D. Norris. 1998. "The Crowded Nest: Young Adults at Home," Canadian Social Trends, Spring 1999, No. 52, pp. 2-5.

Cherlin. A.J., K.E. Kiernan, and P.L. Chase-Landale. 1995. "Parental Divorce in Childhood and Demographic Outcomes in Young Adulthood," Demography 32: 299-318. 
Early Life Transitions of Canadian Youth:

Effects of Family Transformations and Community Characteristiics

Coleman, J. S.1988. "Social Capital in the Creation of Human Capital," American Journal of Sociology 94: S95-121.

Coleman, J.S. 1990. Foundations of Social Theory. Cambridge, MA: Belknap Press of Harvard University Press.

Elder, G. H. Jr. 1995. The Life Course Paradigm: Social Change and Individual Development, in P. Moen, G.H. Elder, Jr. and K. Lusher (eds) Examining Lives in Context: Perspectives on the Ecology of Human Development. Washington, D.C.: American Psychological Association. Pp. 101-139.

Fussell, E. 2002. The Transition to Adulthood in Aging Societies. In F.F. Furstenberg, Jr. (ed) Early Adulthood in Cross-National Perspective. Thousand Oaks, CA: Sage Publications. Pp. 16-39.

Giele, J.Z. and G.H. Elder, Jr. (eds) 1998. Methods of Life Course Research, Qualitative and Quantitative Approaches. Thousand Oaks, CA: Sage Publications.

Glaeser, E. L. 2001. "The Formation of Social Capital," Isuma: Canadian Journal of Policy Research 2(1): 34-40.

Hagan, J., R. MacMillan, and B. Wheaton. 1996. "The Life Course Effects of Family Migration on Children," American Sociological Review 61(3): 368-385.

Hogan, D.P.1980. "The Transition to Adulthood as a Career Contingency," American Sociological Review 45:262-76

Hogan, D.P. 1981. Transitions and Social Change: The Early Lives of American Men. NY: Academic Press.

Hogan, D.P. and N.M. Astone. 1986. "The Transition to Adulthood," Annual Review of Sociology 12: 109-130.

Kiernan, K. E. 1992. "The Impact of Family Disruption in Childhood on Transitions Made in Young Adult Life," Population Studies 46: 213-234.

Kiernan, K. E. and A. Cherlin. 1998. Parental Divorce and Partnership Dissolution in Adulthood: Evidence from a British Cohort Study. Hopkins Population Center Papers on Population: WP 98-03. 
Zenaida R. Ravanera, Fernando Rajulton and Thomas K. Burch

Lapierre-Adamcyk, E., C. Le Bourdais and K. Lehrhaupt, 1995. "Le départ du foyer parental des jeunes Canadiens nés entre 1921 et 1960," Population 50(4-5): 1111-1136.

Le Bourdais C. and N. Marcil-Gratton. 1998. The Impact of Family Disruption in Childhood on Demographic Outcomes in Young Adulthood, in Corak, M. (ed). Labour Markets, Social Institutions and the Future of Canada's Children. Ottawa: Statistics Canada, cat. no. 89-553: 91-

Marcil-Gratton, N., C. Le Bourdais, and E. Lapierre-Adamcyk. 2000. "The Implications of Parents' Conjugal Histories for Children," Isuma: Canadian Journal of Policy Research 1 (2): 32-40.

Marini, M.M. 1984a. "The Order of Events in the Transition to Adulthood," Sociology of Education 57(2): 63-84.

Marini, M.M. 1984b. "Age and Sequencing Norms in the Transition to Adulthood," Social Forces 63(1): 229-44.

McLanahan, S. 1985. "Family Structure and the Reproduction of Poverty," American Journal of Sociology 90: 873-901.

McLanahan, S. and L.L. Bumpass. 1988. "Intergenerational Consequences of Family Disruption," American Journal of Sociology 94: 130-52.

McLanahan, S. and G. Sandefur. 1994. Growing Up With a Single Parent: What Helps, What Hurts. Cambridge, MA: Harvard University Press.

Mitchell, B. 1994. "Family Structure and Leaving the Nest: A Social Resource Perspective," Sociological Perspectives 37(4): 651-671.

Mitchell, B.A., A.V. Wister, T.K. Burch. 1989. "The Family Environment and Leaving the Parental Home," Journal of Marriage and the Family 51: 605-613.

Mortimer, J. T., C. Harley, and P.J. Aronson. 1999. How Do Prior Experiences in the Workplace Set the Stage for Transitions to Adulthood, in A. Booth, A.C. Crouter, and M.J. Shanahan (eds) Transitions to Adulthood in a Changing Economy: No Work, No Family, No Future? Westport: Praeger. Pp. 131-159. 
Early Life Transitions of Canadian Youth:

Effects of Family Transformations and Community Characteristiics

Musick, K. and L. Bumpass. 1999. How Do Prior Experiences in the Family Affect Transitions to Adulthood, in A. Booth, A.C. Crouter, and M.J. Shanahan (eds) Transitions to Adulthood in a Changing Economy: No Work, No Family, No Future? Westport: Praeger. Pp. 69-102.

Portes, A. 1998. "Social Capital: Its Origins and Applications in Modern Sociology," Annual Review of Sociology 24: 1-24.

Presser, H.B. 1989. "Can We Make Time for Children? The Economy, Work Schedules, and Child Care," Demography 26: 523-43.

Putnam, R.D. 2000. Bowling Alone : The Collapse and Revival of American Community. New York : Simon \& Schuster.

Rajulton, F. 2001. "Analysis of Life Histories: A State Space Approach," Canadian Studies in Population 28: 341-59.

Ravanera, Z. and F. Rajulton. 2001. Integration at Late Life: Inclusion, Participation, and Belonging among the Elderly. Population Studies Centre Discussion Paper 01- 16. Paper presented at the 2001 Meeting of the Federation of Canadian Demographers. Ottawa.

Ravanera, Z. F. Rajulton, and T. K. Burch.1995. "A Cohort Analysis of Home-leaving in Canada 1910-1975," Journal of Comparative Family Studies. 26 (2): 179-194.

Ravanera, Z. F. Rajulton, and T. K. Burch.1998. "Early Life Transitions of Canadian Women: A Cohort Analysis of Timing, Sequences, and Variations," European Journal of Population 14: 179-204.

Ravanera, Z.R. F. Rajulton, T.K. Burch and C. Le Bourdais. 2002. "The Early Life Courses of Canadian Men: Analysis of Timing and Sequences of Events," Canadian Studies in Population. 29: 293-312.

Ravanera, Z., F. Rajulton, and P. Turcotte. (Forthcoming). "Youth Integration and Social Capital: An Analysis of the Canadian General Social Surveys on Time Use," Youth and Society.

Shanahan, M. J. 2000. "Pathways to Adulthood in Changing Societies: Variability and Mechanisms in Life Course Perspective," Annual Review of Sociology 26: 667-92.

Zhao, J.S., F. Rajulton, and Z. R. Ravanera. 1995. "Leaving Parental Homes in Canada: Effects of Family Structure, Gender, and Culture," Canadian Journal of Sociology 20: 31-50. 